\title{
Time Engineers: An Interactive Multimedia Program for Secondary School Students
}

\author{
Eric W. Johnson \\ Valparaiso University
}

\begin{abstract}
This paper describes a unique outreach vehicle, an interactive multimedia program, that introduces secondary school students to different principles in engineering. The program, called Time Engineers, allows students to travel to different time periods and work through engineering-related activities. The goal of each activity is to encourage the development of reasoning and problem solving skills, and at the same time, introduce one or more engineering principles. Starting this fall, the CD-ROM will be distributed to school systems where teachers can enhance their curriculum with the activities found in the program.
\end{abstract}

An initial version of the program which included one time period and four activities was distributed in the spring of 1998 to seven different middle and high schools in Northwest Indiana. Teachers incorporated the activities into classes ranging from algebra to physics. The response by both teachers and students was overwhelming positive. Teachers were excited about using the program to supplement their existing curriculum and the students had fun learning about different engineering principles.

\section{Introduction}

Statistics show that there is a pressing need for new engineers and this shortage will likely continue into the next century. To help alleviate this problem, both industry and universities must work harder at promoting engineering and engineering-related careers at the secondary school level. Recently, the Sloan foundation released an excellent set of multimedia materials aimed at educating students about careers in engineering ${ }^{1}$. These materials provide valuable information for high school seniors and college freshman who have already decided that they are interested in a science or engineering-related career. Over the past ten years there have also been numerous summer workshops held at universities around the country for middle and high school students. These types of workshops have been very successful at introducing engineering to a limited group of students (many of which have been hand selected to participate). In contrast, the goal of this project was to motivate a large number of students including those who may have not thought about pursuing engineering or engineering-related careers. These include students in primarily rural or urban schools. Since it may not be feasible to bring a large number of secondary students to a university campus, another approach for reaching these students is to bring the basic engineering principles into their classroom. For this approach to be successful, however, two things must occur. First, the project brought to the schools must be interesting enough that students would not only learn about engineering but also be motivated to consider engineering careers, and second, secondary school teachers have to be willing to incorporate the 
project into their existing curriculum with minimal effort. Without the support of the teachers, any project brought into the schools will fail.

The result of this project has been the development of Time Engineers, an interactive multimedia program designed to help middle and high school students explore and apply some fundamental principles of engineering. The program employs a gameplay environment in which students can travel to the different time periods and help solve engineering problems that occurred at that time. Each of the time periods contain two activities from a specific engineering discipline, Civil, Mechanical, Electrical or Computer. The activities are designed to be highly interactive and open-ended. The students may spend five minutes or five hours on each of the activities. At this time there have been three time periods incorporated into the program: Ancient Egypt, World War II and the Middle Ages.

The program can be run in two modes. A user can work through the entire program which includes finding the time pod and jumping to the different time periods (interactive mode) or a user can access pull-down menus and go directly to the various activities (activity mode). The interactive mode allows the user to move through the program similar to a game environment. They control when to move and choose what time period to travel to. While this interaction may be fun and exciting for a single person, it is not practical in a classroom environment. Therefore, the activity mode allows teachers to bypass movement through the program and go directly to any one of the activities in any time period. A view of the time pod as it is found in an old factory is shown in Figure 1.

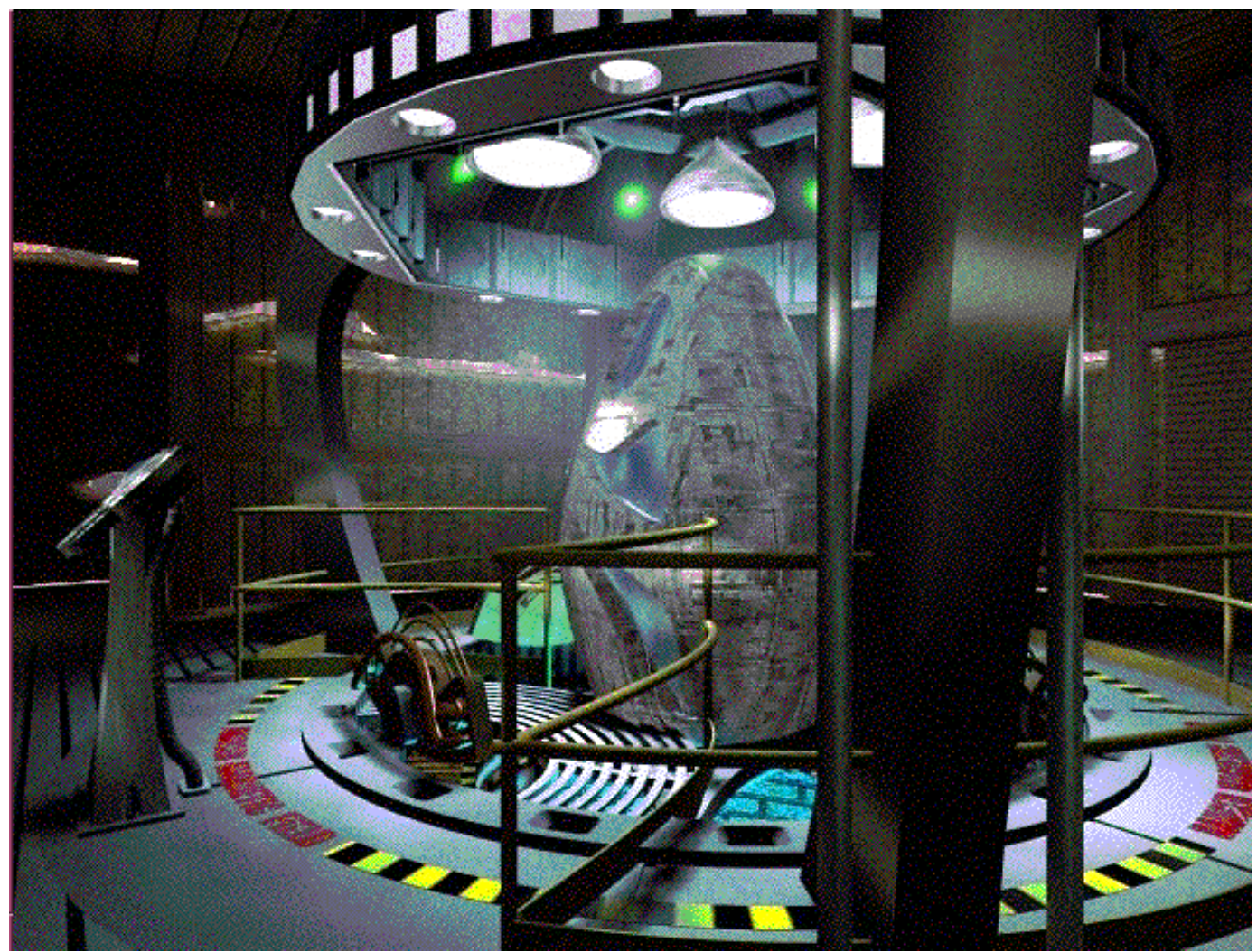

Figure 1. Side View of the Time Pod stored in an Abandoned Factory 
The program has been initially designed for an IBM-compatible personal computer with a Pentium processor running either Windows 95/98 or Windows NT. It can be run either from the CD-ROM or copied onto the hard drive and executed locally. There are plans to port the program to the MAC-OS in the future.

\section{Activity Description}

The main component in the program is the activities. Each activity is centered around an engineering principle. The principle may be a a fundamental law or a set of equations that describes some engineering phenomenon. It is important to note that a person using the program does not need to understand the specific engineering principle utilized to be successful at a given activity. Each activity, however, does offer extra information that allows users to learn more about the science and mathematics involved with these principles. These information sections serve as mini-lessons that students or teachers can view asynchronously. The idea for this type of activity, one in which the user can enjoy the activity and then learn more about the theory, came from working with the West Point Bridge Designer².

The interface for one of the activities from Ancient Egypt is shown in Figure 2 on the following page. In this activity students help build one level of a pyramid. The engineering principle is the static forces involved with moving a stone up a ramp (friction, weight, pulling force). Students participate in the activity by choosing three parameters: the length of the ramp used to haul the stones, the type of material the ramp is made of (sand or clay) and the number of workers used to pull the stone up the ramp. As they choose the ramp parameters, the ramp appears on the screen in the correct proportions. Then when they select the BUILD button, an animation will run which allows them to see if the level will be built based on their ramp design parameters. If they do not have enough workers needed to pull the stone up the ramp, a message will appear stating they should either increase the length of the ramp or the number of workers. Cost is also factored into this activity by attaching a price for using either clay or sand and a price for a person moving a stone up the ramp. These costs produce an optimization problem in which students can continually work on the activity trying to minimize the cost to build one level of the pyramid. If they get within $5 \%$ of the minimum cost a congratulatory message appears (as shown in the figure). Other items on the interface include a REPORT button which when selected allows the user to see a history of all of the parameter combinations and results that they have tried so far, an AUDIO button which gives an audio description of the activity, and an INFO button which contains the additional information on the engineering principle utilized in the activity.

The other activities in the program follow the same format. Each of the activities have two to three parameters that the user can select. Some are discrete choices while others allow the user to enter a value within a range. Once the sections are made, an animation is run that will evaluate their design choices. If their selections create an answer that is far from the correct result, a message box will appear offering hints on how they can improve their choices. The activities use a variety of problem formulations. Some, like the example given above, are optimization problems. Others employ probabilities or distribution functions and some simply have one solution. This way students will be introduced not only to a variety of engineering principles but also a variety of problem formulations. 


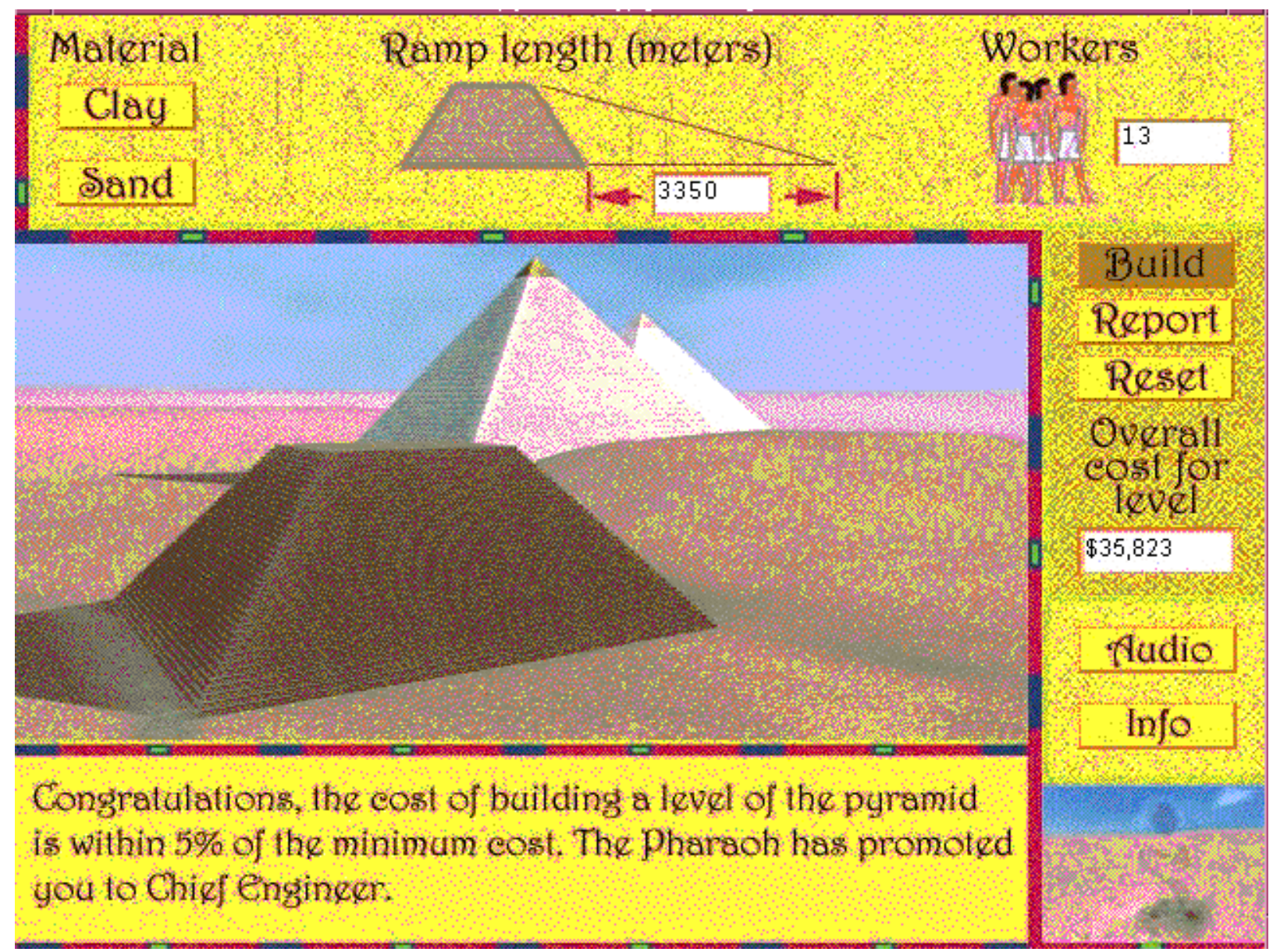

Figure 2. Interface for the Pyramid Building Activity

\section{Secondary School Implementation}

The main objective for developing this program was to have it available for secondary school teachers to use in the classroom. Computer access, however, varies from classroom to classroom and school to school. Teachers may have access to one computer or a full computer lab. This program can be used effectively in either situation. Ideally, individual students or small groups of students (2-3) would have a computer and work through the activities on their own. In this situation the teacher could provide assistance when needed and interject important points when necessary. If a computer lab is not available, however, teachers can also lead the class through an activity on one computer and solicit advice from the students where necessary.

Because the program encourages creative thinking, students may perform the activities using an trial and error approach. While this type of intuitive problem-solving is important, teachers may want to present a more structured methodology in the classroom by linking the activities to principles in mathematics, science, history or some other subject. To support their efforts in the classroom, a teacher's manual is also being developed and will be distributed along with the program. The manual contains a summary of all the activities including what classes they can be used in. A number of sample lesson plans are also included in the manual. As an example, for the 
pyramid building activity described in the previous section, there are a number of possible courses where this activity could be used. These are listed below along with the specific topics the program could enhance.

- Algebra I (slopes, linear expressions)

- Geometry (trig functions)

- Calculus (volume computation)

- Physical Science (forces and motion)

- History (ancient Egypt)

\section{Multimedia Development}

The development of Time Engineers has taken three years. The program was developed using Macromedia Director. A local graphic design company was employed to create all of the graphics and animations (the most time intensive part of the project). All of the activities within each time period were designed by faculty in the college of engineering at Valparaiso University. For each activity, a faculty member had to develop the underlying theory, create Matlab code to model the equations used, and then generate the necessary documentation (information about the engineering principle) that would be included in the program. The author then translated the Matlab routines into Macromedia Director's Lingo language and worked with the graphic designer at incorporating the graphics and animations with the routines. It is important to note that the faculty members were very enthusiastic about working on this project. While they received only a small stipend, they enjoyed developing the activities and seeing how those activities were incorporated into the program.

Early in the development process an advisory board comprised of secondary school teachers, industry representatives and college of engineering faculty members was formed. The main objectives of the board were to make recommendations on the content of the program and to evaluate the various activities as they were finished. Throughout the development, the advice of the board has been invaluable. Their perspectives have made the program more effective and will help the project succeed in the classroom.

In the spring of 1999 a beta version of the program containing four activities and one time period was evaluated. Math and science teachers from seven different area middle and high schools were given the program and an abbreviated teacher's guide. Teachers were asked to use the program in various courses and evaluate its usefulness. They were also asked to have the students evaluate the program. The evaluation forms for both the teachers and the students were adapted from the evaluation format on the Superkids educational software review website ${ }^{3}$. The forms included both quantitative and short answer questions. The student form focused on program usage (was it easy to use, interesting, fun) and evaluation (what did you learn, what did you like best/least, what would you change) while the teacher form focused more on pedagogy and methodology (was program appropriate for your students, gender neutral, which student would benefit most/least from using the program). Over ten teacher and three hundred student evaluations were collected. The results of the evaluations were overwhelmingly positive. A majority of the student comments centered around the high quality graphics and how they enjoyed working through the different activities. The main criticism was the difficulty a user has 
in determining how to move through the time periods while in interactive mode. This critique led to a change in the program that made it easier to move while in that mode. All of the teachers were excited about having an effective supplement to their lessons. Many of them said the students did not want to stop using the program and were excited about receiving the final version.

\section{Distribution and Future Work}

CD-ROMs containing the program will be distributed freely to all secondary schools in Northwest Indiana during the fall of 2000. The author plans to visit many of the schools during the 2000/2001 school year to assist teachers in incorporating the program into their courses and to get feedback on the program. To offer additional support for the teachers, a web site will be created this summer. The web site will contain new lesson plans for the teachers to use along with links to various engineering and engineering-related career resource sites. In the future, workshops for secondary school teachers may be planned which will focus on introducing them to engineering along with using the Time Engineers program. Finally, there has already been some preliminary discussion on the creation of three more time periods. If funding can be secured, these may be added at a future date.

While the main distribution of this program has yet to occur, the initial evaluation in the schools has convinced the author that this type of technology can be used as an effective outreach tool to influence a large number of students and help them develop an interest in engineering or engineering-related careers.

\section{Acknowledgements}

This project was funded under the Project for Science, Mathematics, and Engineering (PSME) grant from the Eli Lilly Endowment, Inc.

Bibliography

1. Green, D., Laker, K., and Wiesner, P., "The Sloan Career Cornerstone Project: Multimedia Career Education for Undergraduates in Engineering, Math, and Science," In the Proceedings of the 1998 ASEE Frontiers in Education Conference, Nov. 1998, pp. 1089-1094.

2. Ressler, S., Nygren, K., Conley, C., "Building Bridges: Computer-Aided Design as a Vehicle for Outreach to high School Students," In the Proceedings of the 1997 ASEE National Conference, Session 2525, June 1997.

3. URL:http://www.superkids.com; Superkids Educational Software Review.

\section{ERIC W. JOHNSON}

Eric W. Johnson is an Assistant Professor of Electrical and Computer Engineering at Valparaiso University. Dr. Johnson received a B.S. degree in Electrical Engineering from Valparaiso University and a M.S. and Ph.D. from the Computer Science and Engineering Dept. at the University of Notre Dame. He has a strong interest in outreach and has held workshops the past three summers for secondary school teachers interested in learning about engineering. 